\title{
Management Information System
}

\author{
Yuanxin Zhang ${ }^{1, \text { a }}$ \\ ${ }^{1}$ School of Data and Computer Science, Sun Yat-sen University, Guangzhou 510006, China \\ asunny100zyx@foxmail.com
}

\begin{abstract}
In this paper, combining the comprehensive level, business functional areas and industry characteristics, we classify the Management Information System in the field of integrated. Firstly, in the introduction, we will discuss the history of the developing concept, Management Information System. And then, under this integrated of classification method, the Management Information System can be divided into Enterprise Resource Planning (ERP), Supply Chain Management (SCM), Customer Relationship Management (CRM), Knowledge and Collaborative Management System (KCMS), Product Life Cycle Management System (PLCM), Enterprise Asset Management Information System (EA - MIS), Accounting Management Information System (AMIS), Human Resource Management Information System (HR - MIS), Project Management Information System (PMIS), Business Intelligence Systems (BIS), This paper will analyze these types so that it can give you a clear understanding of MIS.
\end{abstract}

Key words: Management Information System, Synthesis Classification.

\section{Introduction}

Management Information System is a developing concept. After the 1980s, with the rapid growth of modern management ideas and information technology, management information system has a fast development, the concept of Management Information System gradually enrich and perfect.

The definition of Management Information System firstly appeared in 1970, put forward by Walter T. Kennevan: Management Information System is "in the form of written or oral, providing the past, present, predictive information and the environment information for the manager or the staff in enterprise, to help them to make decisions". We can see that this definition highlights the function of supporting decision making, not related to the requirements of modern information technology, also did not involve the application of the model [1].

In the early 1980 s, the Chinese Enterprise Management Encyclopedia defined as follows: The Management Information System is a system consists of people and computer, can be used of information collection, transmission, storage and processing [2]. Meanwhile, it has been clear about the Management Information System's function is measuring various operation conditions of enterprise, using the past data to predict the future, using information to control the behavior of enterprise, helping enterprise to achieve planning goals. This definition highlights the function and properties of Management Information System, emphasizes the computer is just a tool.

In 1985, the famous professor Gordon Davies (Gordon b. Davis) from University of Minnesota Carlson School of Management, gives the definition which is a very classic one: Management Information System is a man-machine system using of computer hardware, software, artificial regulation, decision model and database, providing information support for the organization's operation, management and decision-making". This definition is more comprehensive, it illustrates the goal, function and composition of Management Information System. 
In order to describe the Management Information System in the enterprise or the role of organization in the field of business management, the famous American professors Landon couple (Kenneth C.Landon \& Jane P.Landon) in their book Management Information System, gives a comprehensive definition: from technical point of view, the Management Information System is a interrelated set of collecting, processing, storing and disseminating information to support making decision within the organization and controlling a collection of parts; from business point of view, the Management Information System is based on information technology, and in order to deal with environmental challenges, there comes organization and management to input, process, output and feedback[3]. As we can see, business perspective emphasizes the characteristics of application, focusing on providing useful information and advanced solutions.

In 1999, the famous scholar professor Huacheng Xue added the "social technology system" and redefine MIS: Management Information System is a people-oriented, using computer hardware, software, network communication equipment and other office equipment, in order to improve the effectiveness and efficiency, collecting, transmitting, processing, storing, updating and maintaining information so that can support enterprises' high-level decision, middle control, basic operation of the integrated man-machine system.

Management Information System is a complex system, its composition and the elements are quite different from different angles. So we not only put its construction into consideration, but also combine the comprehensive level, business functional areas and industry characteristics, to classify the Management Information System in the field of integrated.

\section{Synthesis Classification of Management Information System}

\subsection{Enterprise Resource Planning (ERP)}

ERP is a system which use planning as the core, organize resources in the way of unified planning, management and coordination, its main functions include master production planning, material requirement planning, purchasing management, inventory management, sales management, workshop management, quality management, financial management, human resource management, etc.

ERP systems have been adopted by many companies in recent years due to expectations of lower operating costs, shorter cycle times, and higher customer satisfaction [4].

\subsection{Supply Chain Management (SCM)}

SCM is a system based on e-commerce to manage supply chain, its main functions include logistics management, warehouse management, order management, portal management, etc.

\subsection{Customer Relationship Management (CRM)}

The core of CRM is customer-centric management, including customer management, sales team management, market activity management, and service management,etc.

ERP, SCM, and CRM are widely used in daily work

\subsection{Knowledge and Collaborative Management System (KCMS)}

KCMS is mainly used of knowledge management, resource sharing and collaborative work, its main functions include document management, work-flow engine running, resource sharing, E-mail management, full-text search and knowledge discovery, etc.

Knowledge management refers to gather, organize, share and transfer knowledge so that can improve a series of activities which related to organizational behavior.

\subsection{Product Life Cycle Management System (PLCM)}

In order to manage the whole life-cycle of the product, PLCM system can be applied. PLCM main functions including customer demand management, product design, product data management, 
product portfolio management and product use tracking management, etc.

\subsection{Enterprise Asset Management Information System (EA - MIS)}

For those organizations which mainly manage infrastructure and equipment, such as electric power, energy enterprises, they can use EAMIS. EAMIS provide main functions including asset purchase management, work management, test management, maintenance management and parameter management, etc.

\subsection{Accounting Management Information System (AMIS)}

In view of the financial work, if you want a more comprehensive and in-depth management, you can use the AMIS. Its main function is to manage and integrate financial information and organization of business information.

\subsection{Human Resource Management Information System (HR - MIS)}

It refers to the management and integration of human resources information and organization of business information.

\subsection{Project Management Information System (PMIS)}

To make a comprehensive management of the project schedules, cost, quality, procurement, contracts, equipment, materials and documents, you can use the PMIS.

PMIS can be used in various area, like software engineering. For example, the scholar Fred D. Davis and Viswanath Venkatesh, who both from University of Arkansas, used PMIS to the preprototype user acceptance testing [5]. It can help with big data and make the test can have better information.

\subsection{Business Intelligence Systems (BIS)}

In order to improve the decision-making level, you can with the aid of data warehouse tools, like OLAP tools, data mining tools etc. The system which providing these tools is BIS.

Let list an example. FACETS, is a cognitive business intelligence system which was developed and evaluated based on the situation retrieval (SR) model. The aim of FACETS is to provide decision makers cognitive decision support in ill-structured decision situations. The design and development of FACETS includes novel concepts, models, algorithms and system architecture, such as ontology and experience representation, situation awareness parsing, data warehouse query construction and guided situation presentation.

\section{Conclusion}

We can obviously see that in these classifications, the content of different types of information systems is intersected. For example, the ERP includes the content of human resource management. This means that the classification of the Management Information System is only relative, not absolute. Different types of management information systems have different priorities. People's understanding in the breadth and depth of the Management Information System often varies with time and environment

With the rapid development of world economic globalization, the industry trend of internationalization, enterprises must be able to respond in a timely manner in a rapidly changing environment. In order to meet the challenge of the market, enterprises need to have an accurate grasp on the market, analyze the customer's consumption trend, find out the problems in enterprise management, strengthen the relationship between supply chain partners, new business opportunities, and to make predictions about the future. So, how to make full use of these data assets, unearth the information policymakers need, make high quality decisions is the problem that enterprise managers need to consider.

In recent years, data integration, data analysis, large capacity of data storage and parallel processing technology become more and more slick, and the cost become so much less. Integrated these factors, I think the Management Information System in the direction of promoting business intelligence will be more outstanding performance. Business intelligence based on machine learning 
techniques, you can convert all kinds of data in a timely manner to support decision-making information and knowledge, help enterprise managers to understand the customer's demand, consumption habit, forecast the change trend of the market and the overall development direction of the industry, for effective decision making, thus a good position in the competition.

\section{References}

[1] Jinyi Chang, Management Information Systems, Beijing, 2014, 2-7

[2] Enterprise Management Committee of China, Enterprise Management of China Encyclopedia

[3] Kenneth C. Landon, Carol Guercio Traver, Management Information Systems (12th Edition)

[4] Sally Wright, Arnold M. Wright, Information System Assurance for Enterprise Resource Planning Systems:Unique Risk Considerations

[5] Fred D. Davis, Viswanath Venkatesh, Toward Preprototype User Acceptance Testing of New Information Systems: Implications for Software Project Management 